\title{
Cancer Genetics Services in the UK
}

\author{
Shirley V. Hodgson \\ Division of Medical and Molecular Genetics, \\ Guy's Hospital, London SE1 9RT, UK
}

The National Health Service is the principal provider of free healthcare services, through general practitioners offering primary care to a network of District and Regional or University Teaching hospitals. Medical Genetics has a long history in the UK, although it was not recognised formally until the 1970s. Regional Genetics Centres, providing an integrated clinical and laboratory service, have been established for many years. Most also operate "outreach" clinics at satellite hospitals, or dedicated joint specialist clinics. There are 25 Regional Genetics Centres, each serving a population of 3-6 million: in 1997 they had 79 specialist clinicians (with 55 trainees), and 107 Genetic Counsellors.

Genetic counselling is offered by Consultant Clinical Geneticists (with specialist training), supported by Specialist Registrars in Clinical Genetics and Genetic Nurses or Counsellors. Since the 1970s the UK has had several counsellors attached to each Regional Genetics Centre. In many centres they provide full genetic counselling for many conditions, with the support of a discussion departmental framework. Genetic Counsellors are valuable members of the clinical genetics team, who play a considerable role in the provision of counselling service, thereby reducing the workload of Consultants and Registrars, who can then target particular aspects of the service.

Laboratory diagnostic services are integral parts of the Regional Genetics Centres. In 1997 there were 408 cytogeneticists (with 106 trainees) and 101 molecular geneticists (with 31 trainees). There is now a clear process of laboratory accreditation. The UK network of molecular genetics centres has rationalised testing for mutations in specific genes in certain centres only, by agreement. However, the patenting of genes such as BRCA1 and BRCA2 is likely to have a profound impact on the costs and management of cancer services, and could result in "rationing" of tests to very high-risk families only.

\section{CANCER GENETICS SERVICES}

Cancer genetics referrals have increased greatly over the last ten years, and now comprise approximately half of the genetics referrals in many centres. The Department of Health commissioned a recent review of cancer genetics services from a working group under Prof. Peter Harper [1]. The report of this group has stimulated negotiations to increase funding for cancer genetics services. A similar report was published in 1998 by the Scottish Office (Department of Health), covering Cancer Genetics Services in Scotland. Both reports recommend the establishment of Regional Cancer Genetics Centres, offering services on the basis of agreed risk criteria (judged by family history).

Currently, most specialised genetic counselling for familial cancer is organised by the Regional Genetic Centres. Most run designated Cancer Family Clinics, or operate multi-disciplinary clinics in conjunction with other specialties. Initially many of these were developed on an ad hoc basis, funded from research sources, but NHS funding is now replacing this. The service is becoming more integrated and cohesive with the benefit of discussion fora such as the Cancer Family Study Group, and management guidelines are being developed. In addition, it is increasingly being recognised that general practitioners and specialists 
in other disciplines have an important role to play in the initial recognition of patients and families in need of referral for specialist genetic counselling. It is intended that specialised cancer care be centralised to the specialist units dealing with the care of breast/ colorectal cancer etc., each catering for some 150,000-250,000 people, according to guidelines laid out in the Calman-Hine Report (1995). Individuals at moderately increased risk will be managed in this way, and only high-risk individuals in whose families it is probable that a genetic predisposition is segregating will be seen in the Regional Genetics Centres themselves (serving a population of 3-6 million). Genetic Counsellors will play an important role in evaluating risks for prioritising referrals, and coordinating screening. They are also likely to provide a "gatekeeper" role in primary care.

Audited follow-up is crucial for evidence-based review, facilitated by a fully-documented confidential database recording pedigree data and surveillance outcomes. This requires dedicated data managers, and preferably a coordinated surveillance network. Specialised genetic counsellors might also fill this role.

The Royal College of General Practitioners is currently debating ways of improving education for primary care practitioners, and various other organisations are involved in educational initiatives (for instance, the Genetic Interest Group).

\section{TRAINING OF CANCER GENETICISTS}

- Accreditation of oncologists (and specialists from related disciplines) and clinical geneticists in Cancer Genetics is currently being considered by the Royal Colleges, and the appropriate training for specialist registrars in oncology and genetics wishing to be accredited in cancer genetics is under consideration by the relevant Specialist Advisory Committees.

- The Harper Report emphasised the need to build up expertise at the level of the Calman Centres, which will provide specialised cancer care, under the direction of the Regional Genetics Centre.

Discussion fora:

- The British Society of Human Genetics (formed in 1996) is made up of the Clinical Genetics Society, the Association of Clinical Cytogenetics, the Clinical Molecular Genetics Society and the Genetic Nurses \& Social Workers Association.

- $\quad$ Cancer Family Study Group

- National Cancer Forum

- ICRF Cancer Genetic Nurse Support Group

- Northern Ireland Regional Advisory Committee on Cancer

A number of cancer and genetic registries exist. Many Regional Genetics Centres have registries for specific genetic conditions, including some monogenic cancer-predisposing conditions.

\section{References}

[1] Department of Health (1996) Genetics and Cancer Services. Report of a Working Group for the Chief Medical Officer, Department of Health (Harper Report). 


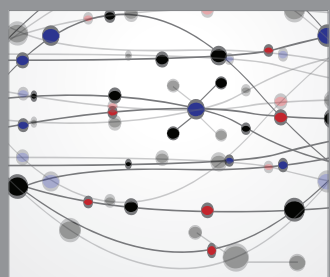

The Scientific World Journal
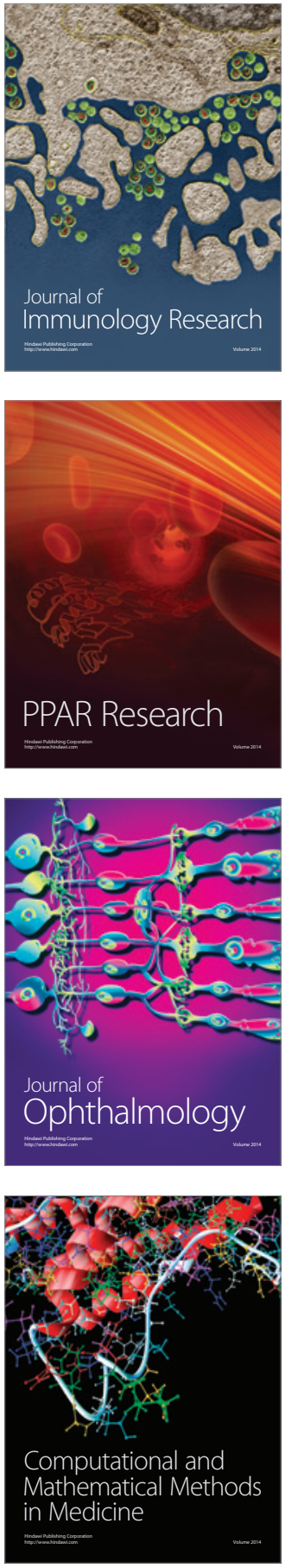

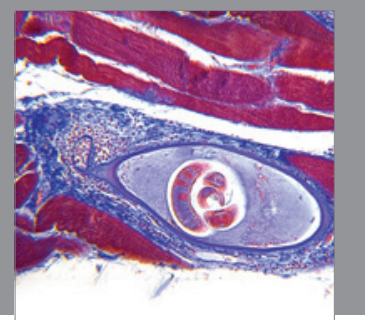

Gastroenterology

Research and Practice
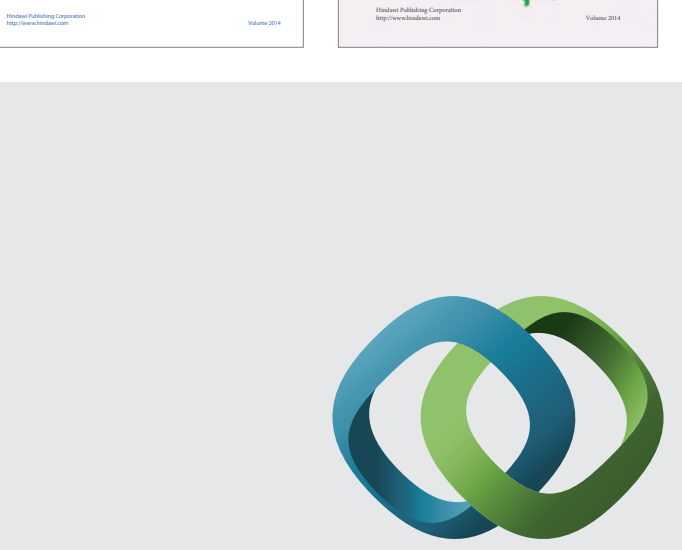

\section{Hindawi}

Submit your manuscripts at

http://www.hindawi.com
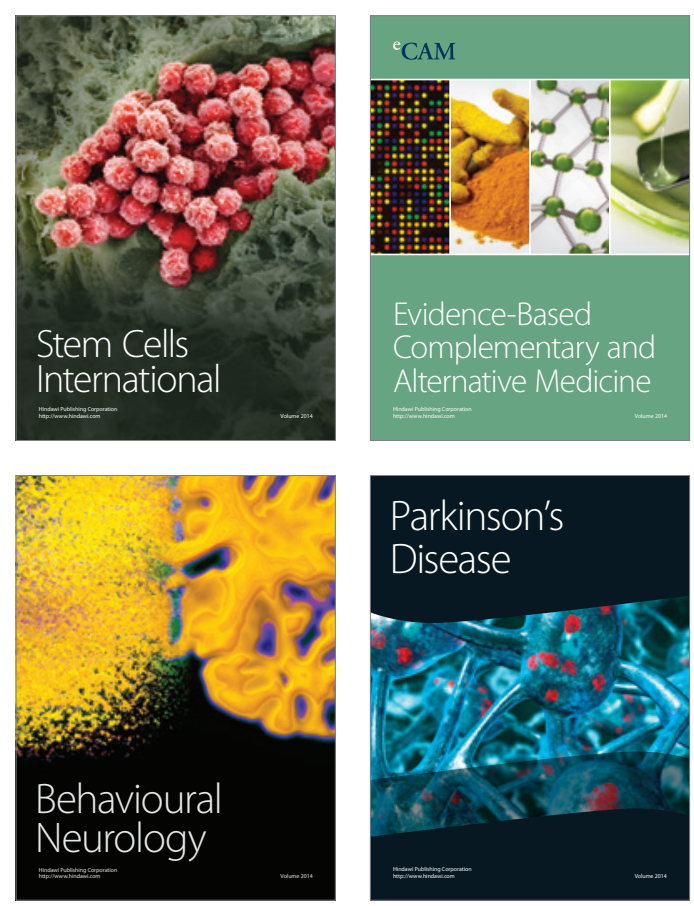

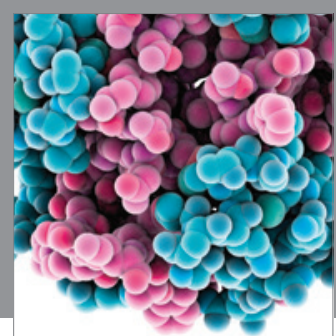

Journal of
Diabetes Research

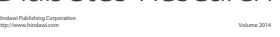

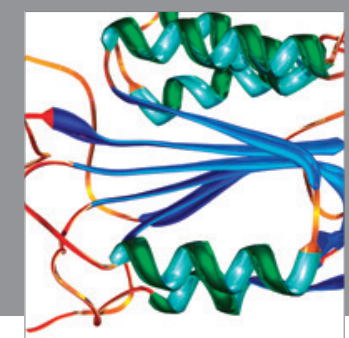

Disease Markers
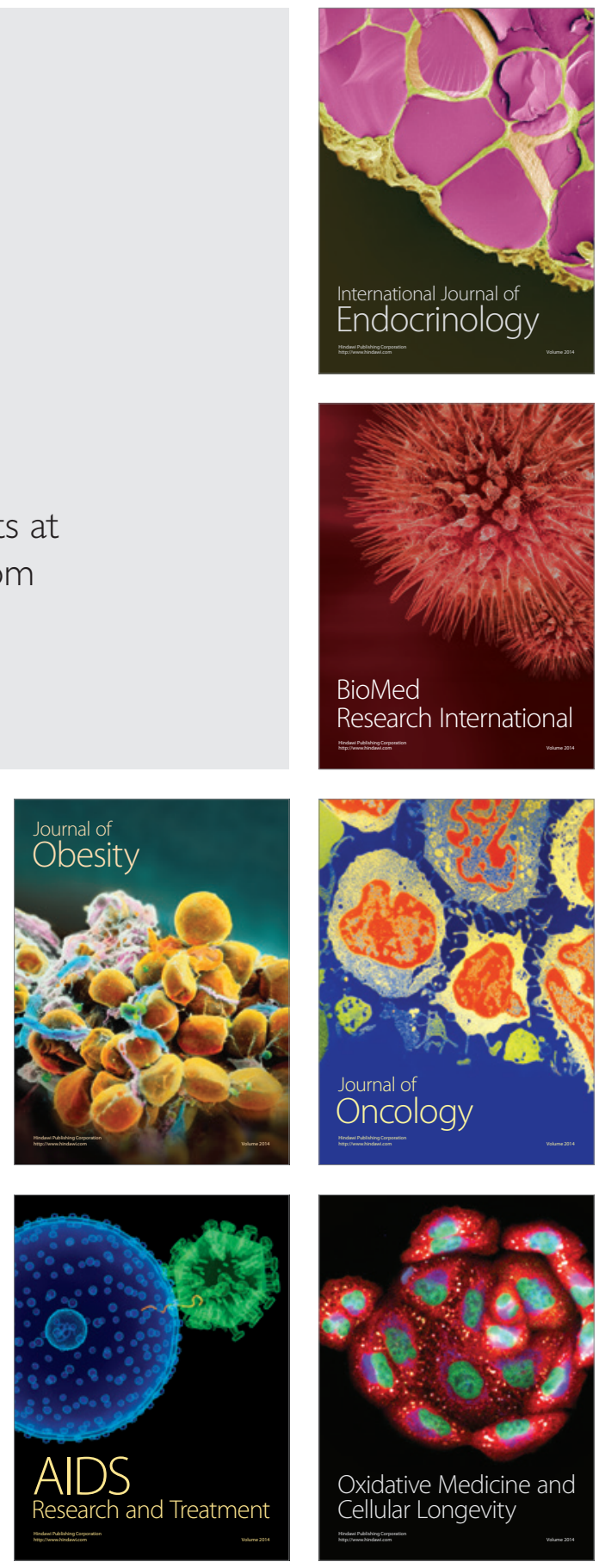